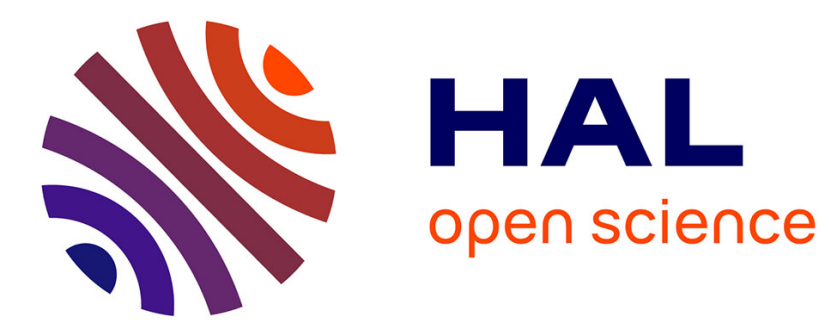

\title{
Sub-regions of the dorsal raphé nucleus receive different inputs from the brainstem
}

\author{
C. Peyron, Claire Rampon, Jean-Marie Petit, Pierre-Hervé Luppi
}

\section{To cite this version:}

C. Peyron, Claire Rampon, Jean-Marie Petit, Pierre-Hervé Luppi. Sub-regions of the dorsal raphé nucleus receive different inputs from the brainstem. Sleep Medicine, 2018, 49, pp.53-63. 10.1016/j.sleep.2018.07.002 . hal-02368923

\section{HAL Id: hal-02368923 \\ https://hal.science/hal-02368923}

Submitted on 23 Nov 2021

HAL is a multi-disciplinary open access archive for the deposit and dissemination of scientific research documents, whether they are published or not. The documents may come from teaching and research institutions in France or abroad, or from public or private research centers.
L'archive ouverte pluridisciplinaire $\mathbf{H A L}$, est destinée au dépôt et à la diffusion de documents scientifiques de niveau recherche, publiés ou non, émanant des établissements d'enseignement et de recherche français ou étrangers, des laboratoires publics ou privés. 
SUB-REGIONS OF THE DORSAL RAPHÉ NULEUS RECEIVE DIFFERENT INPUTS FROM THE BRAINSTEM

Christelle Peyron $^{\mathrm{a}, \mathrm{b}^{*}}$, Claire Rampon ${ }^{\mathrm{a}, \mathrm{c}}$, Jean-Marie Petit ${ }^{\mathrm{a}, \mathrm{d}}$, Pierre-Hervé Luppi ${ }^{\mathrm{a}, \mathrm{b}}$

aINSERM U52, CNRS ERS 5645, University-Lyon1, Lyon, France

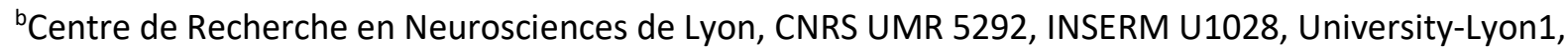
Lyon, France

'Centre de Recherches sur la Cognition animale (CRCA), Centre de Biologie Intégrative (CBI), Université de Toulouse, CNRS, UPS, France

${ }^{d}$ Centre des Neurosciences Psychiatriques, Centre Hospitalier Universitaire Vaudois (CHUV), Prilly, Switzerland

${ }^{*}$ Corresponding author. Centre de Recherche en Neurosciences de Lyon, 7 rue Paradin, 69372 Lyon cedex 08, France.

Phone: +3347877 1042 .

Email address: peyron@sommeil.univ-lyon1.fr (Christelle Peyron)

Key words: serotonin, sleep, mood disorders, arousal 


\section{Preamble}

We could not have dreamt of a better way to enter the world of sleep research: We, CP, CR and JMP, did our doctorate training in Michel Jouvet's laboratory during its last years of research activity.

Michel Jouvet was a great physiologist and a direct heir of Claude Bernard. He belonged to the lineage of clinicians to whom medicine must be primarily "experimental". His work was based on close observations of the animals he recorded and on the conviction that the understanding of phenomena could only come from a multidisciplinary approach.

Thanks to his personality, strength and persuasiveness, his laboratory was a hive composed of more than 50 neuroscientists with complementary expertise in physiology, electrophysiology, pharmacology, neurochemistry and neuroanatomy, welcoming scientists from all over the world. Jouvet's lab was pioneer in studying the genetics of sleep with Jean-Louis Valatx, the phylogeny and the ontogeny of sleep with Danièle Jouvet, Joelle Adrien and Marie-Jo Challamel, the neurochemistry of sleep with Jean-François Pujol and Michel Buda.

Discovering the state of paradoxical sleep implied discovering its functions and its supporting neuronal networks. As early as the mid 70's, in addition to lesion studies and electrophysiological recordings, Jouvet's lab tremendously contributed to the identification of neurochemical nature of cell populations involved in the regulation of the sleep-wake cycle and their interconnections. This was performed thanks to a whole team of great neuroanatomists, namely Kunio Kitahama, Kazuya Sakai, Lucienne Léger, Pierre-Hervé Luppi and Patrice Fort. It is in this stimulating environment that, thanks to their deep knowledge and enthusiasm, we then doctorates, have started our scientific career as neuroanatomists. It is with emotion that we report here original data collected some twenty years ago, under the supervision of Pierre-Hervé Luppi and the fatherly eyes of Michel Jouvet. 


\section{Abstract}

The dorsal raphe nucleus (DRN) through its extensive efferent projections has been implicated in a great variety of physiological and behavioral functions including the regulation of the sleep-wake cycle. This nucleus is composed of 5 sub-regions defined according to the distribution of its serotonergic (5-HT) neurons. In addition to its heterogeneity in neuronal populations, the DRN contains a great diversity of 5-HT neuronal subtypes identified based on their electrophysiological characteristics, morphology and sub-regional distribution. This suggests that the DRN sub-regions may play different functional roles. Recent studies reported long-range inputs specific to the 5-HT neurons of the DRN; but they did not differentiate whether some inputs were specific to a DRN subregion, or another region. To fulfill this gap, we have previously described the forebrain afferents to the different sub-regions of the DRN using cholera toxin b subunit and Phaseolus vulgarisleucoagglutinin, as retrograde and anterograde tracers respectively. In the present work, we provide a detailed map of the brainstem projections to these different sub-regions. We show that if some brainstem structures project homogeneously to all sub-regions, most of the brainstem long-range inputs project in a topographically organized manner onto the DRN and, moreover, that a rich interconnected network is present within the DRN.

\section{Introduction}

Based on the electrophysiological activity of its serotonergic (5-HT) neurons across the sleepwake cycle (ie. active during waking and silent during sleep) [1-3] and their largely distributed efferent projections to the forebrain [4], the dorsal raphe nucleus (DRN) is known to be a wakepromoting structure involved in a broad range of physiological functions and their pathological counterparts such as emotions, nociception, feeding, motor control, sleep-wake regulation and psychiatric disorders [5-9]. The DRN is a complex and heterogeneous structure that can be divided in five sub-regions based on the distribution of its 5-HT neurons, namely a rostral, dorso-central, ventro-central and caudal parts as well as lateral wings. While the ventro-central part contains almost exclusively 5-HT neurons [10], the content in neurotransmitters and neuropeptides of the other sub-regions is heterogeneous. For example, neurons expressing vasointestinal peptides are mainly located in the dorso-central part of the DRN [11], neurotensin neurons are present in the dorso-central part, the rostral and caudal parts of the DRN [12], while somatostatin neurons are mainly located in the lateral wings of the DRN [13]. Some 5-HT neurons co-express glutamate [14] and nitric-oxyde synthase [15] but not GABA. GABAergic neurons are located in the lateral wings, they are almost absent of the DRN midline but are distributed on the sides of 5-HT neurons [16]. In 
addition to the heterogeneous neuronal populations, the DRN also possess a great diversity of 5-HT neuronal subtypes as demonstrated by their electrophysiological and morphological characteristics and their distribution into sub-regions $[2,3,17]$. It is thus likely that different sub-types of DRN $5-H T$ neurons receive a variety of inputs, modulating differentially their activity.

Thanks to the development of new retrograde tracing technologies using modified rabies virus [18], it is now possible to precisely map the inputs of genetically defined neuronal populations in specific brain areas. Experienced with this elegant tool, Weissbourd et al [19] recently identified long-range direct inputs to 5-HT or GABAergic neurons of the DRN and declared that, overall, DRN 5$\mathrm{HT}$ and GABAergic neurons receive inputs from the same brain area but are generally densest onto 5HT neurons. Using a modified version of this technology [20], they were also able to describe local connectivity within the DRN. However, these authors were not able to distinguish from the density of each long-range input onto the different sub-regions of the DRN. In a previous study [21], we described forebrain inputs to the different sub-region of the DRN using retrograde and anterograde tracing techniques. We now report a detailed map of the long-range inputs to the DRN sub-regions that originate from the brainstem. 

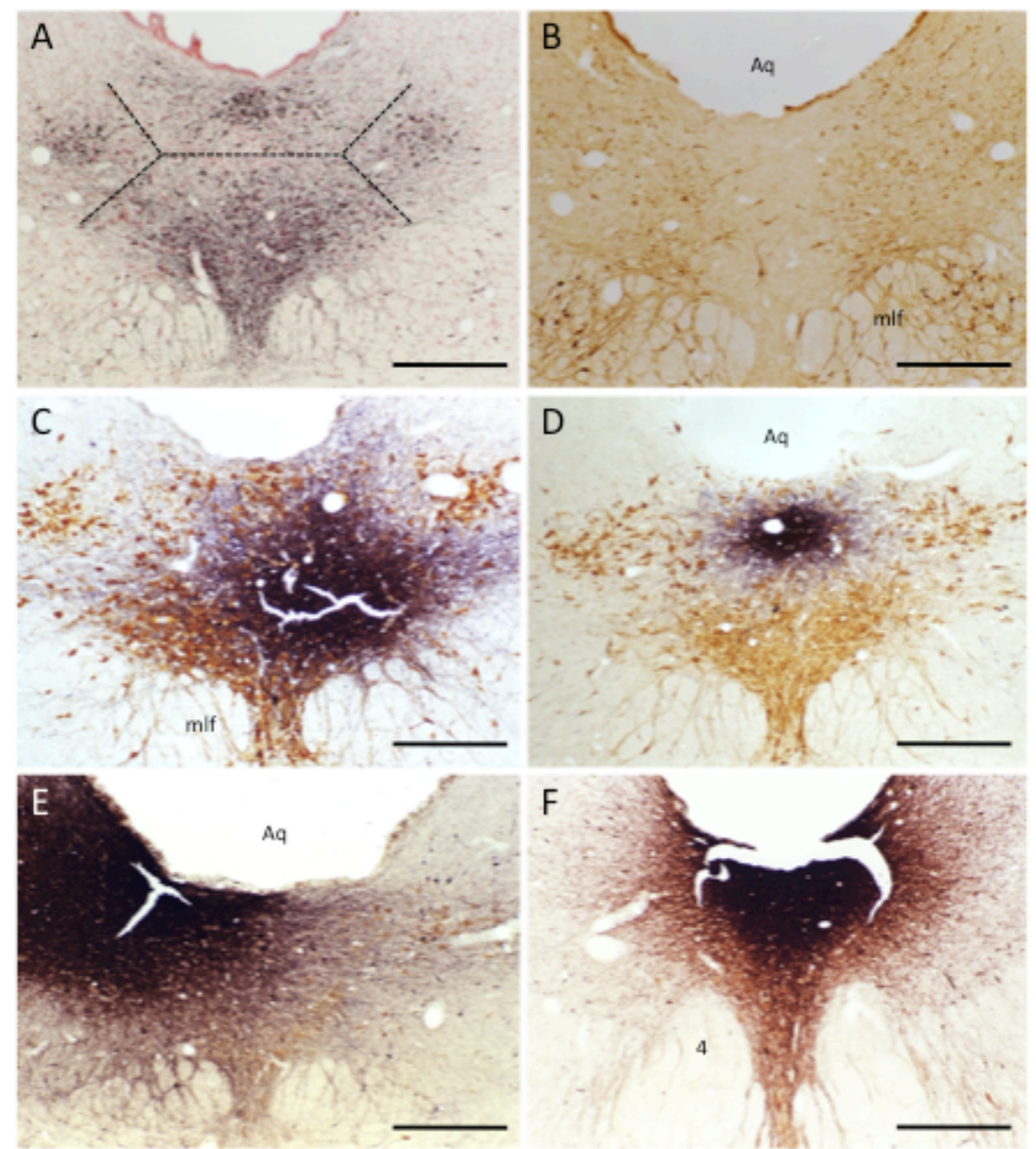

FIG. 1. A, B. Photographs of frontal sections illustrating the distribution (A) of $5-H T$ neurons (in black) in the ventro-central, dorso-central and the lateral wings sub-regions of the DRN on a neutral red counterstained section, and (B) of the GAD-immunoreative neurons (in brown). C-F. Photographs illustrating $\mathrm{CTb}$ injection sites (in black) targeting the ventro-central (C), dorso-central (D), lateral wing (E) and rostral (F) sub-regions of the DRN where 5-HT neurons are orange-brown labeled. Abbreviations: 4: trochlear nucleus; Aq: aqueduct of Sylvius; mlf: medial longitudinal fasciculus. Scale bars $=150 \mu \mathrm{m}$.

\section{Methods}

\subsection{Tracer injection protocol.}

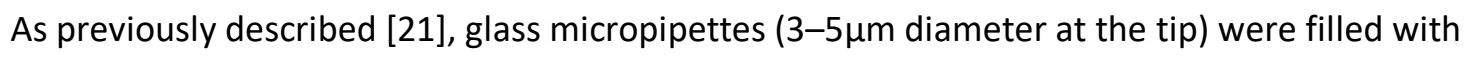
1\% desalted CTb (List Biological Lab.) or Phaseolus vulgaris-leucoagglutinin (PHA-L) solution. Experiments were carried out in accordance with the EU directive guidelines for animal experiments. Prior to CTb injections, male OFA rats (IFFA Credo, France) weighing 260-310g were anaesthetized 
with sodium pentobarbital $(40 \mathrm{mg} / \mathrm{kg}$, i.p.) and placed in a stereotaxic frame. The stereotaxic coordinates of the DRN were defined with the atlas of Paxinos and Watson ([22]; $1 \mathrm{~mm}$ rostral to the interaural, 0-600 $\mu \mathrm{m}$ lateral to midline). An extracellular recording of the 5 -HT-like neurons was done in order to precisely place the tip of the pipette in the DRN sub-regions. CTb was ejected iontophoretically by a $0.5-1 \mu \mathrm{A}$ pulsed positive current $7 \mathrm{~s}$ "on/off" generated by a Midgard CS-4 for 10-15 min in the ventral $(n=10)$ or dorsal $(n=4)$ parts of the central DRN, in the rostral DRN $(n=9)$, or in the lateral wings of the DRN $(n=3)$. Anterograde tracing controls were conducted with PHA-L anterograde tracer in structures determined as afferent to the DRN. PHA-L (2.5\%, Vector labs; 10 $15 \mu \mathrm{m}$ tip micropipettes) was iontophoretically ejected with $5 \mu \mathrm{A}$ pulsed current (7s "on/off' for 15$30 \mathrm{~min})$. Targeted structures were the lateral periaqueductal gray of the pons $(n=2)$, the lateral parabrachial nucleus $(n=6)$, the laterodorsal tegmental nucleus $(n=3)$, the dorsal paragigantocellular area $(n=2)$, the lateral paragigantocellular nucleus $(n=2)$, the locus coeruleus $(n=5)$, the perimesencephalic $V$ area $(n=1)$ and the raphe magnus $(n=3)$.

\subsection{Histology.}

Two weeks after injections, rats were deeply anaesthetized by a sub-lethal dose of pentobarbital and brains rapidly perfused through the ascending aorta with a Ringer-lactate solution containing $0.1 \%$ heparin followed by $500 \mathrm{ml}$ of an ice-cold fixative composed of $4 \%$ paraformaldehyde, $0.25 \%$ glutaraldehyde and $0.2 \%$ picric acid in $0.1 \mathrm{M} \mathrm{PB}(\mathrm{pH} 7.4)$. Then, brains were post-fixed overnight at $4^{\circ} \mathrm{C}$ in the same fixative without glutaraldehyde and cryoprotected in a $30 \%$ sucrose solution for $48 \mathrm{~h}$ at $4^{\circ} \mathrm{C}$. Brains were rapidly frozen at $-30^{\circ} \mathrm{C}$ and sliced on a cryostat in $20 \mu \mathrm{m}$ thick coronal sections. The free-floating sections were stored at $4^{\circ} \mathrm{C}$ in $0.1 \mathrm{M} \mathrm{PB}, \mathrm{pH} 7.4$ containing $0.9 \% \mathrm{NaCl}, 0.3 \%$ Triton $\mathrm{X}-100$ (PBST) and $0.1 \%$ sodium azide (PBST-Az) until use.

\subsection{Immunohistochemistry for CTb.}

Free-floating sections were successively incubated in (i) a goat antiserum to CTb (List Biological Lab., 1:40,000 in PBST-Az) for 3 days at $4^{\circ} \mathrm{C}$; (ii) a biotinylated rabbit anti-goat immunoglobulin (Vector Lab., 1:2000 in PBST) for $90 \mathrm{~min}$ at room temperature (RT); and (iii) streptavidin-HRP (Jackson ImmunoResearch Lab., (1:40,000 in PBST) for 90 min at RT. Incubations were carried out under gentle stirring and stopped by $2 \times 15$ min washes in PBST. Sections were then immersed in $0.025 \%$ 3,3-diaminobenzidine-4HCl solution (DAB; Sigma) containing $0.6 \%$ nickel ammonium sulphate (DAB-Ni) in $0.05 \mathrm{M}$ Tris- $\mathrm{HCl}$ buffer $(\mathrm{pH} 7.6)$ and $0.003 \% \mathrm{H}_{2} \mathrm{O}_{2}$ for $15-30 \mathrm{~min}$ at RT. The reaction was stopped by two rinses in PBST-Az. Finally, the sections were mounted on gelatin-coated glass slides, dried, dehydrated and cover-slipped with Depex.

\subsection{Immunohistochemistry for PHA-L.}


As above, the sections were successively incubated in (i) a rabbit antiserum to PHA-L (DAKO, 1:5000 in PBST-Az) for four days at $4^{\circ} \mathrm{C}$; (ii) a biotinylated goat anti-rabbit immunoglobulin (Vector Lab., 1:2000 in PBST) for 90 min at RT; (iii) streptavidin-HRP (Jackson ImmunoResearch Lab., 1:40,000 in PBST) for 90 min at RT. Finally, the sections were immersed for 10-15min in DAB-Ni.

\subsection{Immunohistochemistry of serotonin.}

Sections were incubated in (i) a rabbit antiserum to serotonin (Incstar Corporation; 1:20,000 in PBST-Az) for four days at $4^{\circ} \mathrm{C}$; (ii) a donkey anti-rabbit immunoglobulin (Jackson ImmunoResearch Lab., 1:1000 in PBST) for $90 \mathrm{~min}$ at RT and (iii) a rabbit peroxidase-antiperoxidase complex (PAP; Dakopatts, 1:1000 in PBST) for 90 min at RT. Then, the sections were immersed for 10-15 min in DAB with or without nickel.

\subsection{Immunohistochemistry of GAD67.}

To label cell bodies of GABAergic neurons, immunoshistochemistry for GAD67, the synthesis enzyme of GABA, was performed. As reported previously [23] pretreatment with $80 \mathrm{mg}$ of colchicine (Sigma) in $4 \mathrm{ml}$ of $\mathrm{NaCl} 0.9 \%$ was intracerebroventricularly injected 2 days before perfusion/fixation. Brain sections were incubated in (1) a 3\% swine serum for 90 min (Life Technologies, Rockville, MD), (2) a rabbit antiserum to GAD with $1 \%$ of swine serum over $3-4$ days at $4^{\circ} \mathrm{C}(1: 10,000$; Chemicon International, Temecula, CA), (3) a donkey biotinylated anti-rabbit IgG (1:1000; Vector); and (4) ABCHRP (1:1000; Elite kit, Vector), both for 90 min at RT. Finally, GAD67 was revealed by DAB.

\subsection{Data analysis of the retrograde labeling.}

Sections immunostained for CTb were analyzed with a computerized image analysis system (Biocom, France). Outlines of sections and major structures were drawn at low power magnification (2.5x) while retrograde-labeled cells were plotted at higher magnification (16x). To determine the respective contribution of each structure projecting to the DRN, counts of the retrograde-labeled cells were made on sections taken every $160 \mu \mathrm{m}$ in each structure on one hemisphere. The number of sections counted for each structure depended on its rostro-caudal extension. The number of afferent neurons was counted from rats injected in the ventro-central DRN $(n=5)$, the dorso-central DRN $(n=3)$, the lateral wings of the DRN $(n=2)$ and the rostral DRN $(n=3)$ (Table 1). Maps from representative large injections (700-800 $\mu$ m diameters) in the ventral (RD27), dorsal (S5) parts of the central DRN, lateral wing (K1) and rostral DRN (N4) are illustrated in figures 2,3,5-7. The photomicrographs were taken with a Kodak Ektar film (25 ASA) using a Leitz Ortoplan microscope connected to a camera (Vario-orthomat). The negatives were then scanned and the digital microphotographs were stored on a Kodak Photo CD disk. To get an optimal reproduction of the CTb and PHA-L stainings, we modified contrast, luminosity and color dominance of the crude scans with 
Photoshop 3.0 (Adobe).

\section{Results}

Based on the distribution of the 5-HT neurons, as previously reported [21], the DRN can be divided into five sub-regions, the rostral and caudal parts, the dorso-central and ventro-central parts and the lateral wings (Fig. 1A). The ventro-central DRN is located just dorsally to the medial longitudinal fasciculi at the level of the anterior tegmental nucleus. The dorso-central part is situated on the midline, just ventrally to the aqueduct. The rostral DRN is located at the level of the trochlear motor nucleus and the caudal DRN lies at the level of the ventral tegmental nucleus of Gudden. Besides 5-HT neurons, the DRN also contains GABAergic cells which distribution is mainly avoiding the central midline of the nucleus (Fig. 1B). To identify the specific brainstem inputs to these DRN sub-regions, we have injected the CTb retrograde tracer in each of them (Figs. 1 C-F) and analyzed retrograde-labeled cells. Of interest, the same animals were used in a previous study reporting forebrain inputs to the DRN sub-regions [21]. 
A
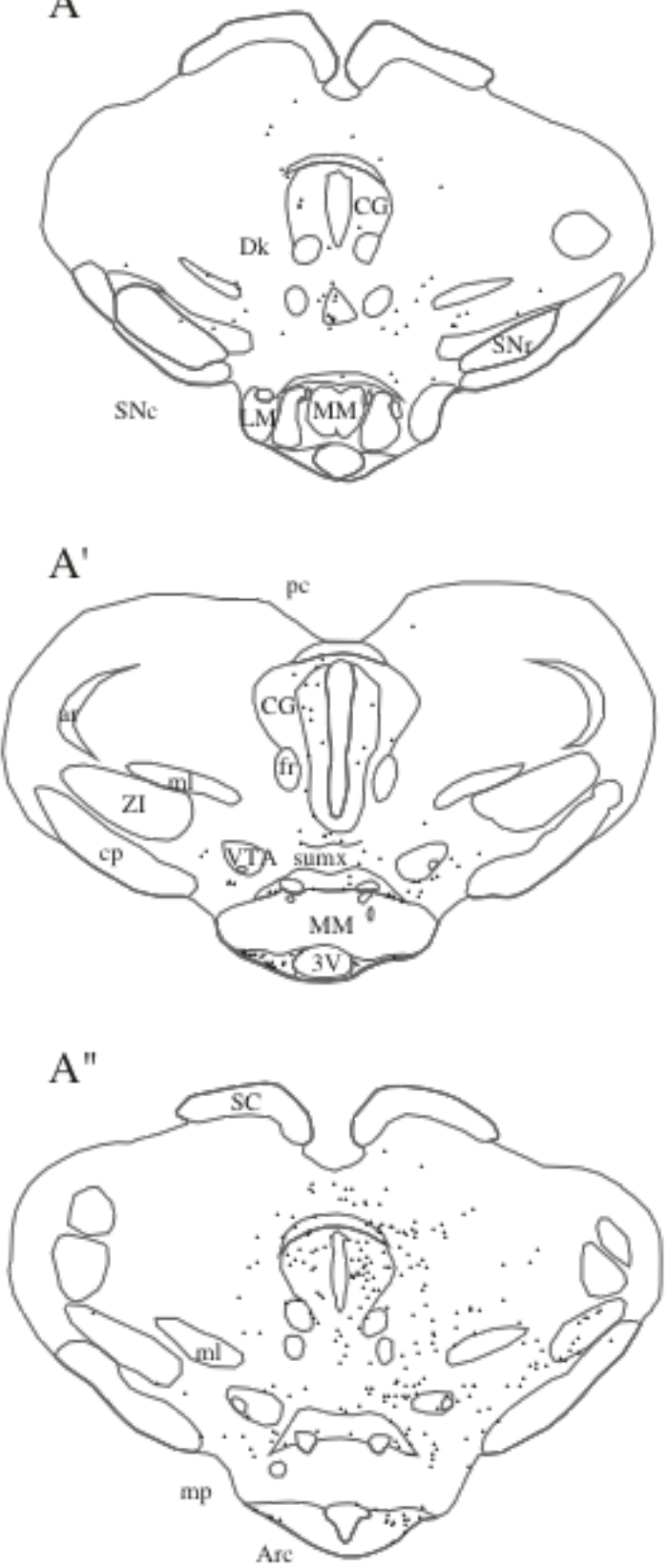

B

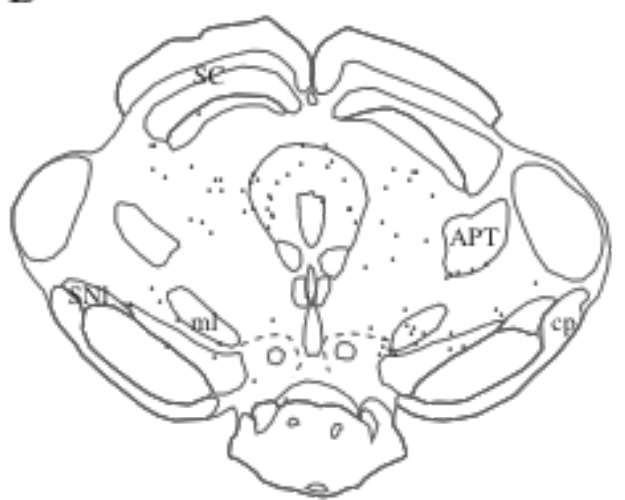

$\mathrm{B}^{\prime}$

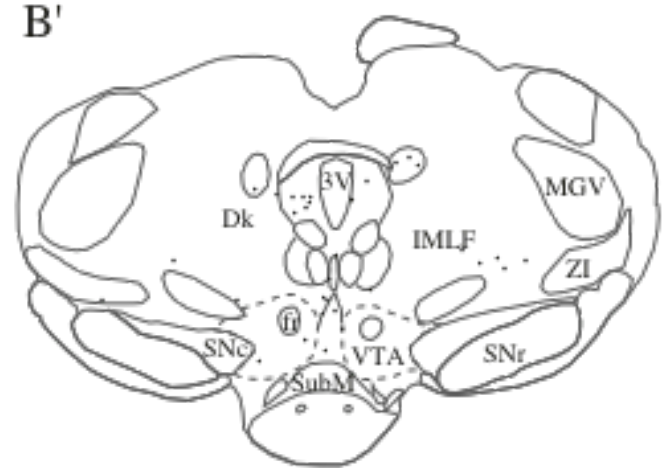

B"

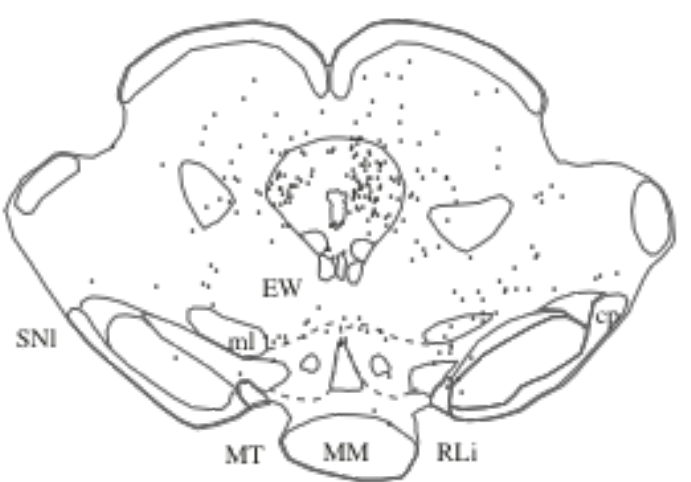

FIG. 2. Drawings illustrating the distribution of retrograde-labeled cells in the mesencephalon after CTb injections in the ventro-central DRN (A-B), the dorso-central DRN $\left(A^{\prime}-B^{\prime}\right)$ or the lateral wings of the DRN ( $\left.\mathrm{A}^{\prime \prime}-\mathrm{B}^{\prime \prime}\right)$. Each black dot represents a CTb retrograde-labeled neuron. 3V: third ventricle; APT: anterior pretectal nucleus; Arc: arcuate nucleus; CG: central gray; cp: cerebral peduncle; Dk: nucleus of Darkschewitsch; IMLF: interstitial nucleus of the medial longitudinal fasciculus; EW: EdingerWestphal nucleus; fr: fasciculus retroflexus; LM: lateral mammillary nucleus; MGV: medial geniculate nucleus; ml: medial lemniscus; MM: medial mammillary nucleus; mp: mammillary peduncle; MT: tuberomammillary nucleus; pc: posterior commissure; RLi: rostral linear nucleus of the raphe; SNc: substantia nigra, compact; SNI: substantia nigra, lateral; SNr: substantia nigra, reticular; SC: superior 
colliculus; suM: supramammillary nucleus; sumx: supramammillary decussation; VTA: ventral tegmental area; ZI: zona incerta.

A

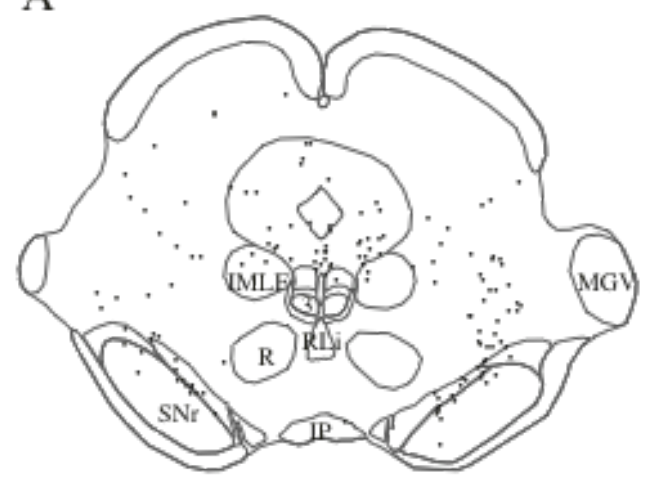

$\mathrm{A}^{\prime}$

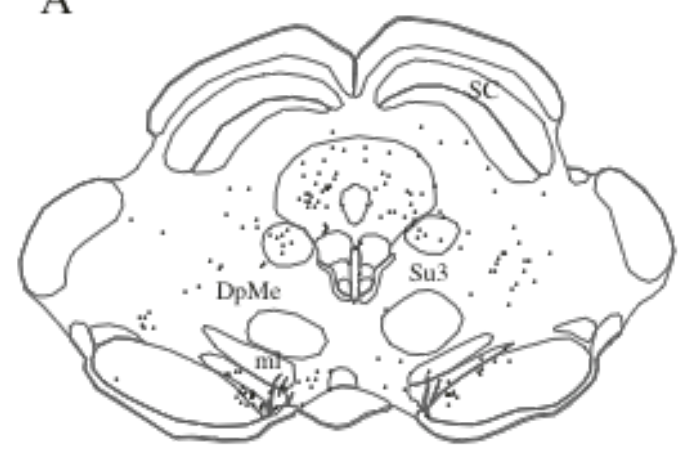

$\mathrm{A}^{\prime \prime}$

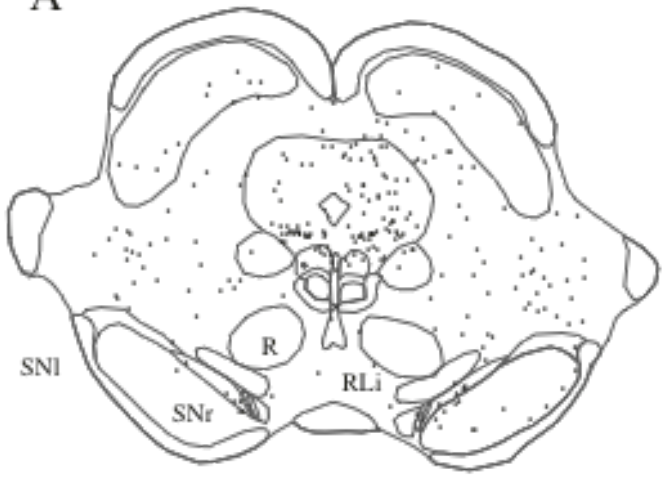

B

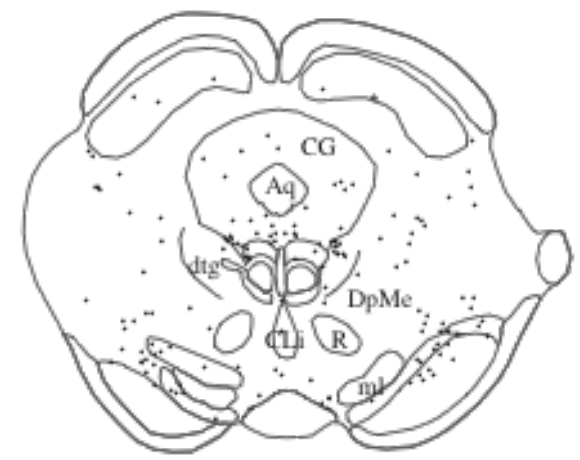

B'

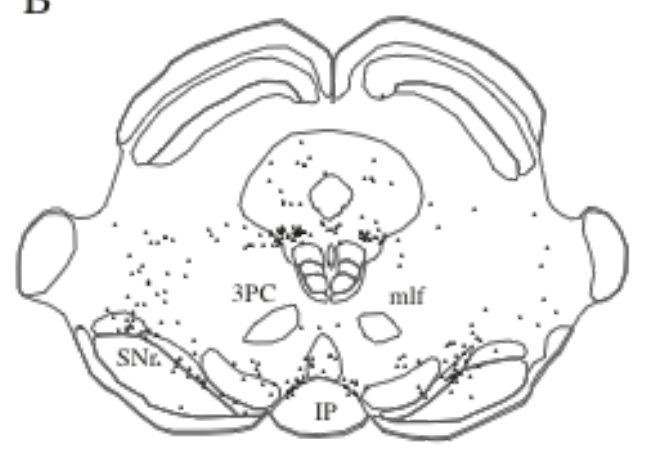

B"

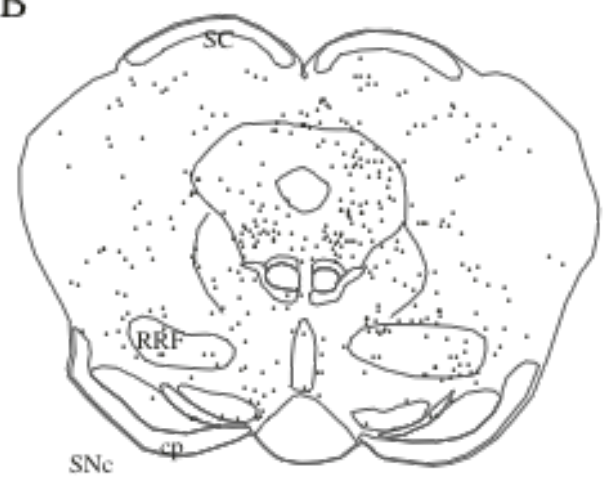

FIG. 3. Drawings illustrating the distribution of retrograde-labeled cells in the mesencephalon after CTb injections in the ventro-central DRN (A-B), the dorso-central DRN $\left(A^{\prime}-B^{\prime}\right)$ or the lateral wings of the DRN ( $\left.A^{\prime \prime}-B^{\prime \prime}\right)$. Each black dot represents a CTb retrograde-labeled neuron. 3: oculomotor nucleus; 3PC: oculomotor nucleus, parvicellular; Aq: aqueduct of Sylvius; CG: central gray; CLi: caudate linear nucleus of the raphe; $\mathrm{cp}$ : cerebral peduncle; dtg: dorsal tegmental bundle; DpMe: deep mesencephalic nucleus; IMLF: interstitial nucleus of the medial longitudinal fasciculus; IP: interpeduncular nucleus; MGV: medial geniculate nucleus medial; ml: medial lemniscus; mlf: medial 
longitudinal fasciculus; R: red nucleus; RLi: rostral linear nucleus of the raphe; RRF: retrorubral field; SNc: substantia nigra, compact; SNI: substantia nigra, lateral; SNr: substantia nigra, reticular; SC: superior colliculus; Su3: supraoculomotor nucleus.

The respective contribution of each input to the different sub-regions of the DRN was evaluated by comparing the number of retrograde-labeled cells in the different brainstem nuclei (Figs 2,3,5-7). Density of efferent projections to the different sub-regions is detailed in table 1 . We found structures similarly and strongly labeled following CTb injections in the different sub-regions of the DRN, namely the mesencephalic periaqueductal gray (Figs. 2-4), the mesencephalic reticular formation, the lateral parabrachial nucleus, the oral pontine reticular formation and the dorsal paragigantocellular area (Table 1) indicating no topographical organization of their terminals in the DRN. In contrary, many nuclei projected preferentially to a sub-region of the DRN. Interestingly, the number of brainstem nuclei sending axonal projections to the ventro-central DRN was limited compare to those projecting to the other sub-regions. The main inputs to the ventro-central part, in addition to those cited above, were the pontine ventrolateral central gray and the paramedian nucleus (Table 1).

The brainstem nuclei projecting preferentially to the dorso-central DRN were the substantia nigra, the superior colliculi, the pontine central gray (except its dorsal part), the laterodorsal tegmental nucleus, the dorsal subcoeruleus nucleus and the caudal part of the nucleus of the solitary tract (Table 1). Brainstem nuclei projecting preferentially to the lateral wings of the DRN were the dorsal and dorsolateral pontine central gray, the median raphe nucleus, the medial parabrachial nucleus, the kölliker-Fuse and the gigantocellular reticular nuclei.

Of interest, we noticed that a densely packed group of retrograde-labeled cells was located in the ventral mesencephalic central gray at the level of the 3rd oculomotor nuclei following all CTb injections (Figs. 4A-B). In addition, we identified a group of retrograde-labeled cells (we named the undefined pontine nucleus) located lateral to the laterodorsal tegmental nucleus and projecting preferentially to the central DRN (Fig. 4C, Table 1). Finally, all PHA-L anterograde-tracing experiments confirmed the topographical organization revealed by using retrograde labeling and reported in table 1 (data not shown). 

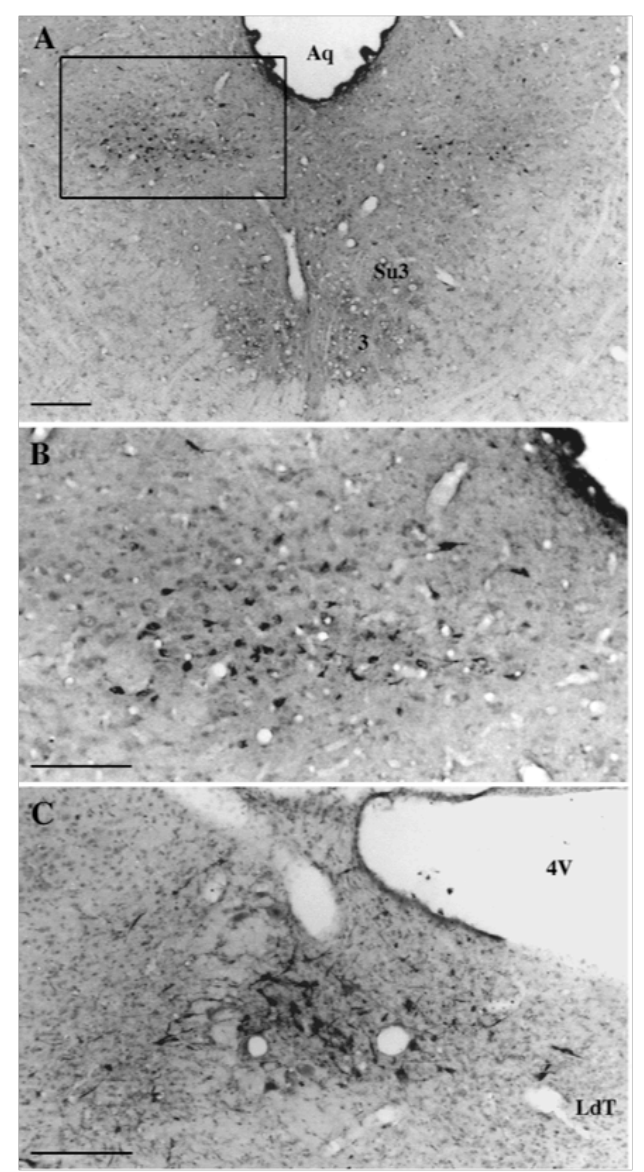

FIG. 4. Photograph of frontal section following CTb immunoshistochemistry illustrating (A) a compact group of small-sized neurons in the ventral mesencephalic central gray (A) after CTb injection in the ventro-central sub-region of the DRN. B is an enlargement of the inner box of A. C. Photograph of the compact group of CTb-labeled neurons in the undefined nucleus located lateral to the lateral tegmental nucleus following the CTb injection in the ventro-central DRN. Scale bars $=200 \mu \mathrm{m}$. 3: oculomotor nucleus; 4V: fourth ventricle; Aq: aqueduct of sylvius; LdT: lateral tegmental nucleus; Su3: supraocculomotor nucleus. 
A

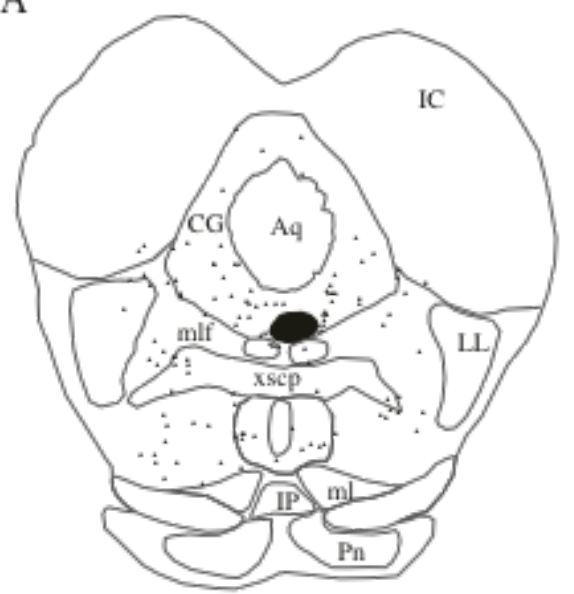

$\mathrm{A}^{\prime}$

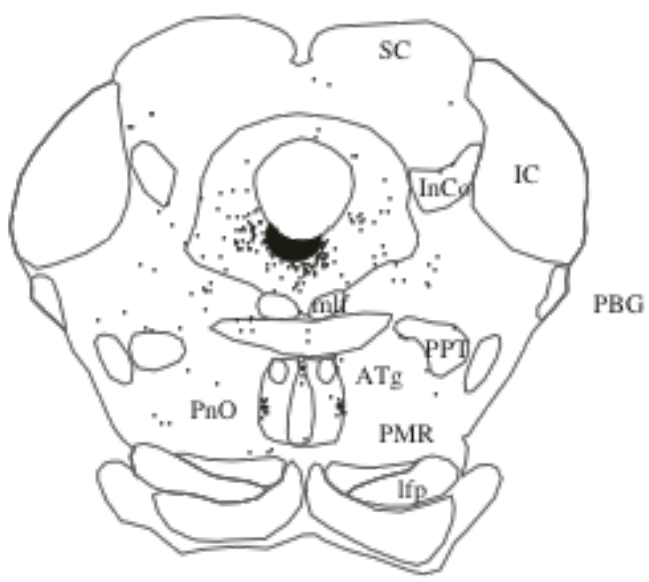

A"

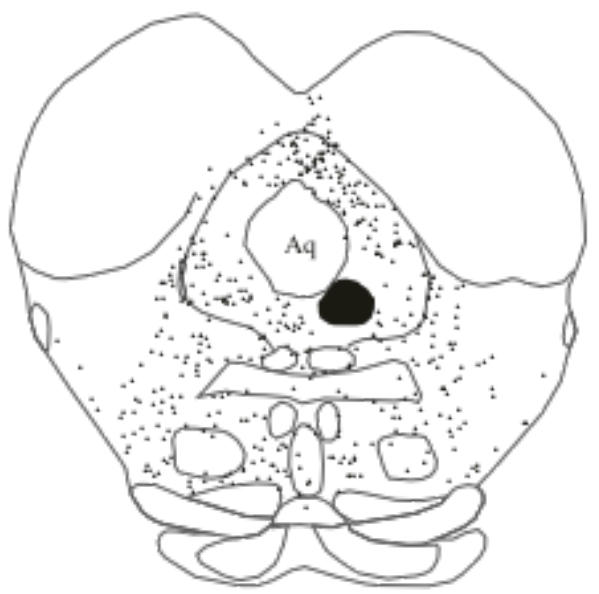

B

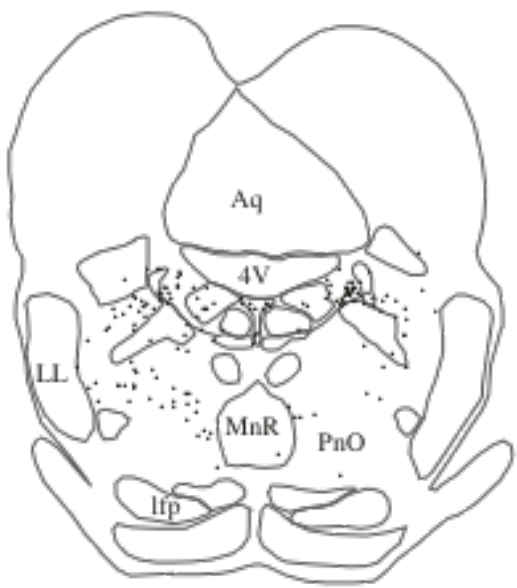

$\mathrm{B}^{\prime}$

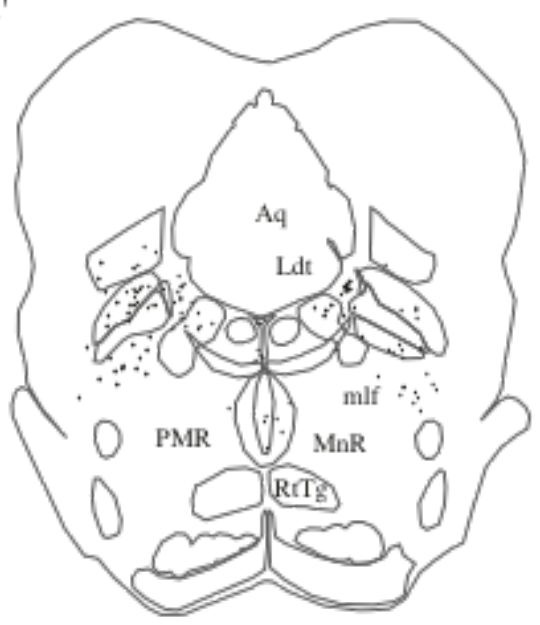

B"

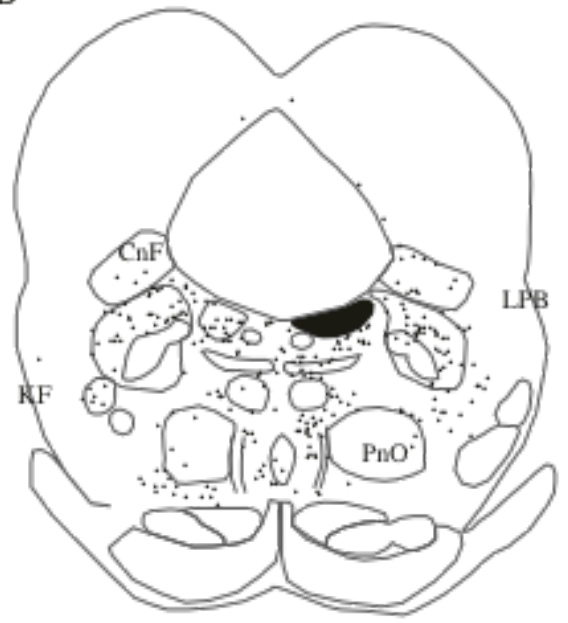

FIG. 5. Drawings illustrating the distribution of retrograde-labeled cells in the pons after CTb injections in the ventro-central DRN (A-B), the dorso-central DRN $\left(A^{\prime}-B^{\prime}\right)$ or the lateral wings of the DRN ( $\left.A^{\prime \prime}-B^{\prime \prime}\right)$. Each black dot represents a retrograde-labeled neuron. The blacked area illustrate the CTb injection-sites. 4V: fourth ventricle; Aq: aqueduct of Sylvius; ATg: anterior tegmental nucleus; 
CG: central gray; CnF: cuneiform nucleus; IC: inferior colliculus; InCo: intercollicular nucleus; IP: interpeduncular nucleus; KF: Kölliker-Fuse; LdT: lateral tegmental nucleus; Ifp: Iongitudinal fasciculus of the pons; LL: lateral lemniscus ; LPB: lateral parabrachial nucleus; ml: medial lemniscus; mlf: medial longitudinal fasciculus; MnR: median raphe nucleus; PBG: parabigeminal nucleus; PMR: paramedian raphe nucleus; $\mathrm{Pn}$ : pontine nucleus; PnO: pontine reticular nucleus, oral ; PPT: pedunculopontin tegmental nucleus; RtTg: reticulotegmental nucleus of the pons; SC: superior colliculus; xscp: decussation of the superior cerebellar peduncle.

A

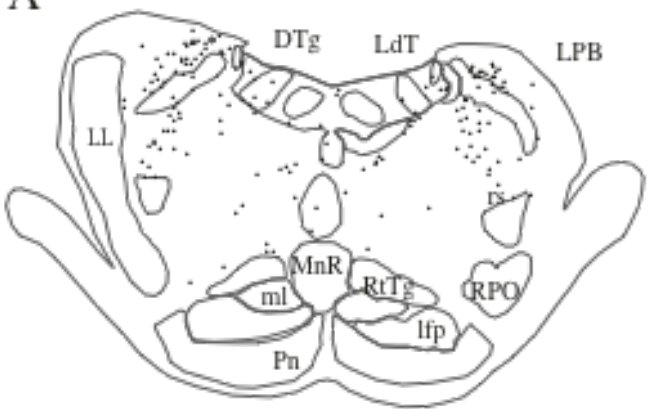

$\mathrm{A}^{\prime}$

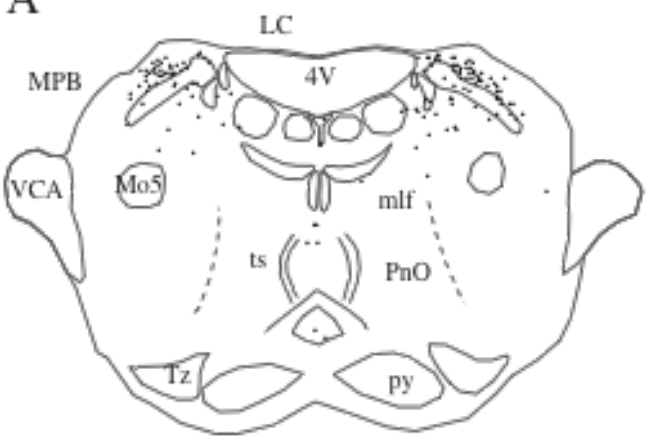

$\mathrm{A}^{\prime \prime}$

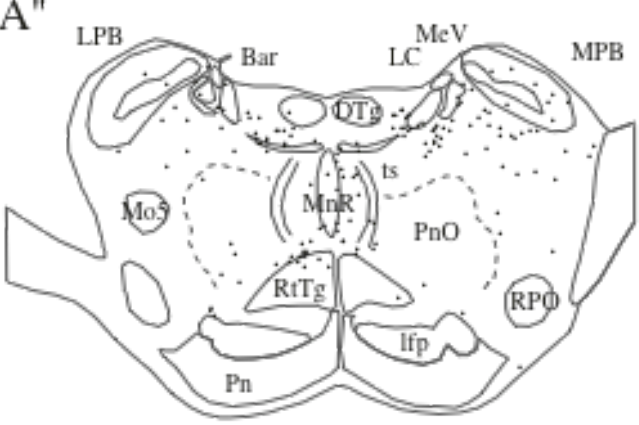

B

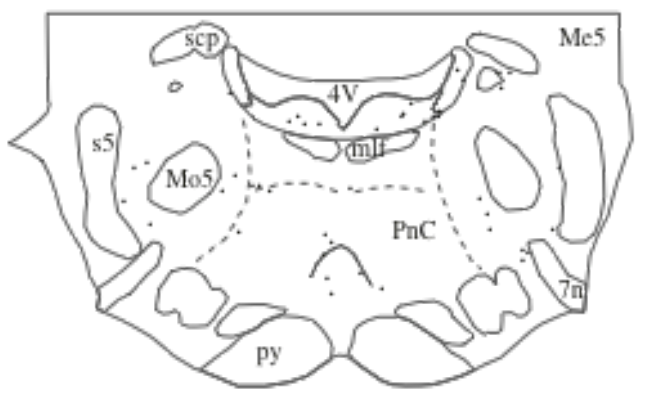

$B^{\prime}$

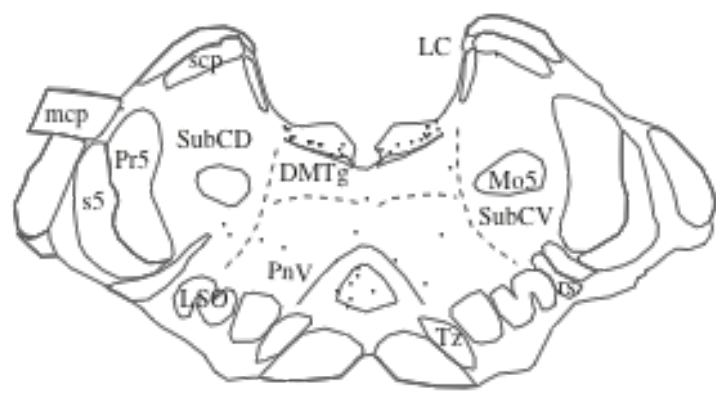

B"

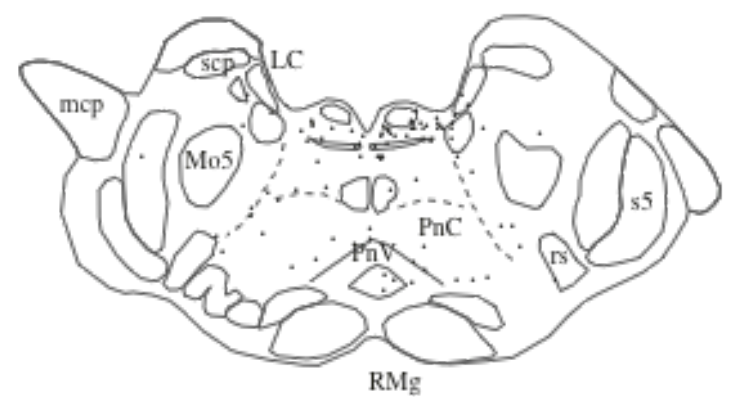

FIG. 6. Drawings illustrating the distribution of retrograde-labeled cells in the caudal pons after CTb injections in the ventro-central DRN (A-B), the dorso-central DRN $\left(A^{\prime}-B^{\prime}\right)$ or the lateral wings of the DRN ( $\left.A^{\prime \prime}-B^{\prime \prime}\right)$. Each black dot represents a CTb retrograde-labeled neuron. 4V: fourth ventricle; $7 \mathrm{n}$, facial nerve; Bar: Barrington nucleus; DTg: dorsal tegmental nucleus; DMTg: dorsomedial tegmental area; LC: locus coeruleus; LdT: lateral tegmental nucleus; Ifp: longitudinal fasciculus of the pons; LL: lateral lemniscus; LPB: lateral parabrachial nucleus; LSO: lateral superior olive; mcp: middle 
cerebellar peduncle; MeV: mesencephalic trigeminal nucleus; ml: medial lemniscus; mlf: medial longitudinal fasciculus; MnR: median raphe nucleus; Mo5: motor trigeminal nucleus; MPB: medial parabrachial nucleus; Pn: pontine nucleus; PnC: pontine reticular nucleus, caudal; PnO: pontine reticular nucleus, oral; PnV: pontine reticular nucleus, ventral; Pr5: principal sensory trigeminal nucleus; py : pyramidal tract; RPO: rostral periolivary region; RMg: Magnus raphe nucleus; rs: rubrospinal tract; RtTg: reticulotegmental nucleus of the pons; s5: sensory root of the trigeminal nerve; scp: superior cerebellar peduncle; SubCD: subcoeruleus, dorsal; SubCV: subcoeruleus, ventral; ts: tectospinal tract; Tz: nucleus of the trapezoid body; VCA: ventral cochlear nucleus, anterior.

A

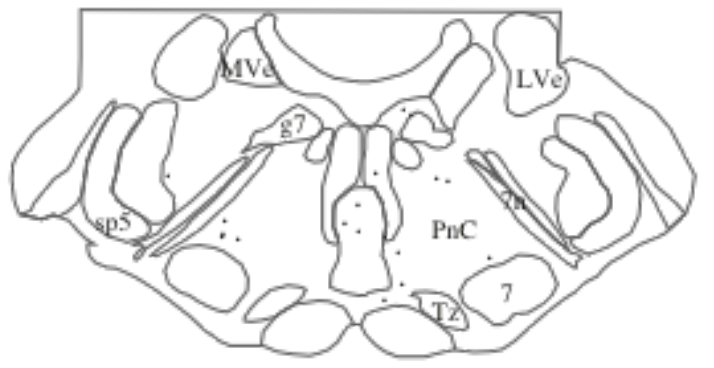

$\mathrm{A}^{\prime}$
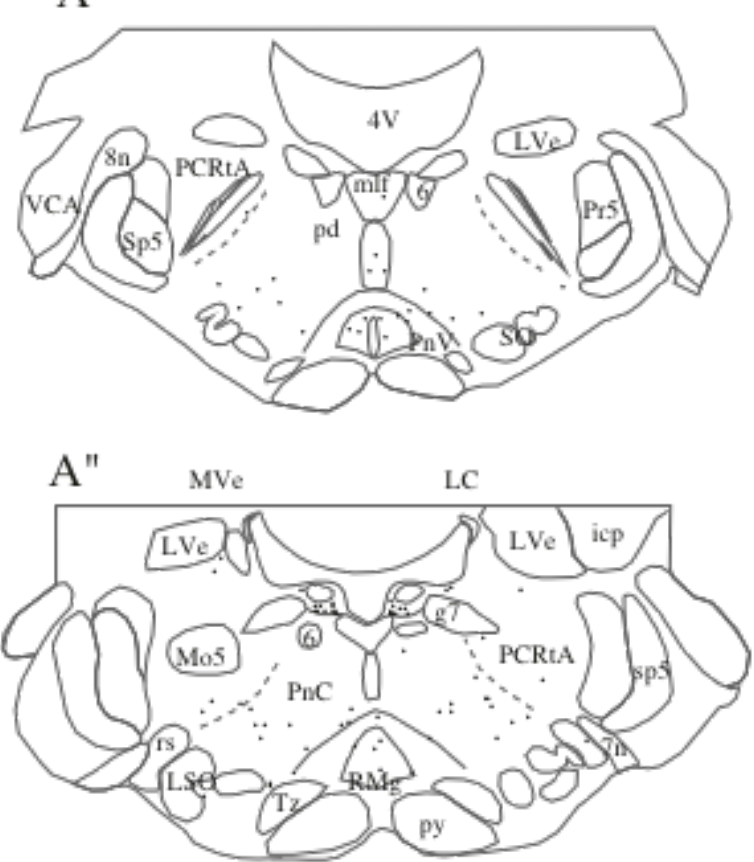

B

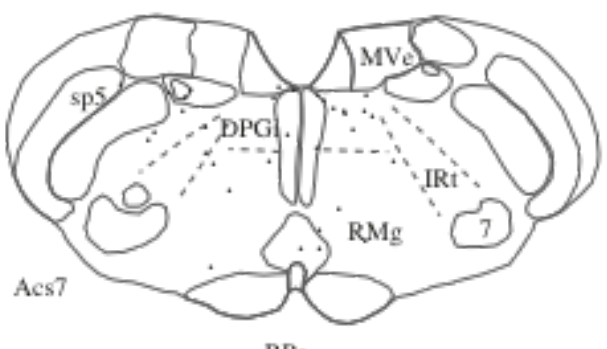

$\mathrm{B}^{\prime}$

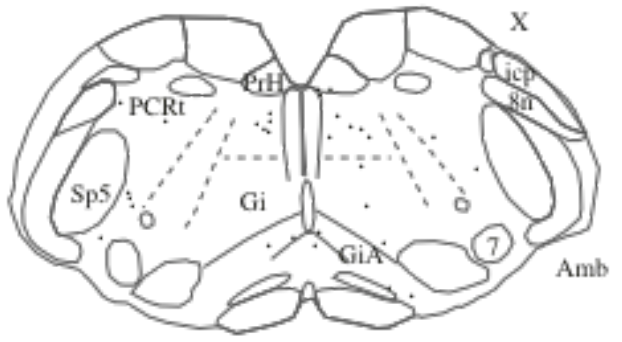

B"

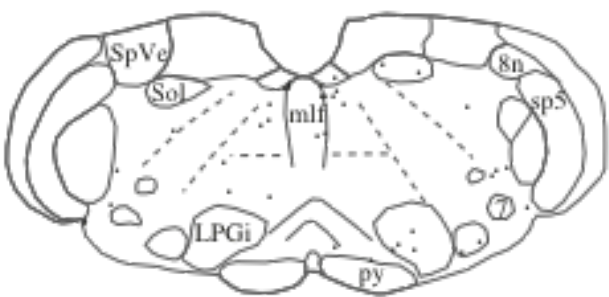

FIG. 7. Drawings illustrating the distribution of retrograde-labeled cells in the medulla after CTb injections in the ventro-central DRN (A-B), the dorso-central DRN $\left(A^{\prime}-B^{\prime}\right)$ or the lateral wings of the DRN ( $\left.A^{\prime \prime}-B^{\prime \prime}\right)$. Each black dot represents a CTb retrograde-labeled neuron. 4V: fourth ventricle; 6 : abducens motor nucleus; 7: facial motor nucleus; 7n: facial nerve; $8 \mathrm{n}$ : vestibulocochlear nerve; Acs7: ascending fibers of the facial nerve; Amb: ambiguus nucleus; DPGi: dorsal paragigantocellular 
nucleus; g7: genu of the facial nerve; Gi: gigantocellular reticular nucleus; GiA: gigantocellular reticular nucleus, alpha; icp: inferior cerebellar peduncle; IRt: intermediate reticular nucleus; LC: locus coeruleus; LPGi: lateral paragigantocellular nucleus; LSO: lateral superior olive; LVe: lateral vestibular nucleus; mlf: medial longitudinal fasciculus; MVe: medial vestibular nucleus; PCRt: parvocellular reticular nucleus; PCRtA: parvocellular reticular nucleus, alpha; pd: predorsal bundle; $\mathrm{Pn}$ : pontine nucleus; Mo5: motor trigeminal nucleus; PnC: pontine reticular nucleus, caudal; PnV: pontine reticular nucleus, ventral; Pr5: principal sensory trigeminal nucleus; PrH: praepositus hypoglossi; py : pyramidal tract; RMg: Magnus raphe nucleus; RPa: Pallidus raphe nucleus; rs: rubrospinal tract; SO: superior olive; Sol: nucleus of the solitary tract; Sp5: spinal trigeminal nucleus; sp5: spinal trigeminal tract; SpVe: spinal vestibular nucleus; Tz: nucleus of the trapezoid body; VCA: ventral cochlear nucleus, anterior; $\mathrm{X}$ : nucleus $\mathrm{X}$.

\section{Discussion}

In the present work, we provide a detailed map of brainstem projections to the different subregions of the DRN. If some structures project homogeneously to all sub-regions of the DRN (ie. the lateral parabrachial nucleus, the pontine ventrolateral central gray, the pontine oralis nucleus, the dorsal paragigantocellular nucleus), we also show that most brainstem long-range inputs project to the DRN in a topographically organized manner. For instance, the supramammillary nucleus, the substantia nigra, the ventral tegmental area and the dorsal subcoeruleus preferentially send their projections to the dorso-central DRN. In contrast, the dorsal central gray, the median raphe nucleus, the ventral subcoeruleus and the gigantocellular reticular area preferentially project to the lateral wings of the DRN. However, no brainstem areas projected preferentially to the ventro-central DRN. Finally we found a rich local connectivity between sub-regions of the DRN.

\subsection{Technical considerations.}

We used retrograde and anterograde tracing techniques available twenty years ago which do not allow the discrimination of a specific neurochemically defined neuronal population as it is now possible with viral vectors technology. Nevertheless, iontophoretic injections of CTb with glass pipettes have demonstrated high tracing efficiency [21,24], are devoid of lesions at the site of injection, thus avoiding the capture of CTb by fibers of passage [25]. Another major advantage of this technique is that injections sites are restricted to small area. Injection sites as small as $150 \mu \mathrm{m}$ in diameter can be obtained, allowing the identification of inputs to a very limited brain sub-region. We were thus able to uncover the local interconnections between sub-regions and neighboring central 
gray, and our data are corroborated by the recent description of Weissbourd and colleagues [19] using viral vector tracing technology.

4.2. Potential role of brainstem inputs to DRN sub-regions in regards to the sleep-wake cycle.

DRN 5-HT neurons are generally considered as waking neurons. This is supported by the fact that the DRN receives convergent excitatory inputs from wake-active neurons located in the forebrain such as, for example, the orexin/hypocretin neurons of the lateral hypothalamus that fire during wakefulness and are nearly silent during sleep [26-28]. In regards to brainstem projections, we show here by retrograde and anterograde tracing that all DRN sub-regions receive a weak projection from the wake-active locus coeruleus and a strong projection from the wake-promoting lateral parabrachial nucleus. In agreement with our data, the lateral parabrachial nucleus, a hypercapnic sensitive region, was shown to trigger arousal via its glutamatergic inputs to many wakepromoting nuclei, including the DRN $[29,30]$.

We have previously reported that 5-HT DRN neurons are submitted to a GABAergic tonic inhibition during sleep [23]. We found that the inhibitory brainstem projections shared by all DRN sub-regions are originating from the ventrolateral central gray and the dorsal paragigantocellular nucleus. Electrophysiological data from our laboratory also revealed that neurons of these two structures are particularly active during paradoxical sleep [31,32] indicating that they are good candidates to keep 5-HT neurons silent during sleep. Interestingly, we also showed in a previous study [33] that the compact group of neurons of the ventral mesencephalic central gray projecting to all sub-regions of the DRN is in part glycinergic in nature, possibly participating to the inhibition of the 5-HT neurons during sleep.

Finally, several subtypes of 5-HT neurons have been distinguished based on their different electrophysiological characteristics across the sleep wake cycle [2,3]. It is likely that their firing profile may relate to the differential innervation received by the different sub-regions of the DRN, that we have uncovered here.

Although not self-sufficient, the knowledge of a brain region connectome is highly informative of its potential function. Based on the present observations, we can propose that the ventro-central DRN may promote wakefulness in a generalized manner, while the dorso-central DRN and its lateral wings receiving strong inputs from the nucleus of the solitary tract and the lateral paragigantocellular nuclei, known to relay autonomic command signals, would rather promote arousal based on signals coming from the periphery.

\section{Contributions}


$\mathrm{CP}$ performed experiments, did the analyses and wrote the manuscript; CR and JMP performed experiments; PHL designed the experiments and provided training in neuroanatomy to $\mathrm{CP}, \mathrm{CR}$ and JMP.

\section{Acknowledgements}

We dedicate this publication to Michel Jouvet. We thank the French ministry for higher education and research, CNRS and INSERM for financial supports.

\section{Conflicts of interest}

The authors have no conflicts of interest

\section{References}

[1] McGinty DJ, Harper RM. Dorsal raphe neurons: depression of firing during sleep in cats. Brain Res 1976;101(3):569-75.

[2] Urbain N, Creamer K, Debonnel G. Electrophysiological diversity of the dorsal raphe cells across the sleep-wake cycle of the rat. J Physiol 2006;573(Pt 3):679-95.

[3] Sakai K. Sleep-waking discharge profiles of dorsal raphe nucleus neurons in mice. Neuroscience 2011;197:200-24.

[4] Vertes RP. A PHA-L analysis of ascending projections of the dorsal raphe nucleus in the rat. J Comp Neurol 1991;313(4):643-68.

[5] Jouvet $\mathrm{M}$. The role of monoamines and acetylcholine-containing neurons in the regulation of the sleep-waking cycle. Ergeb Physiol 1972;64:166-307.

[6] Himmerich $\mathrm{H}$, Treasure J. Psychopharmacological advances in eating disorders. Expert Rev Clin Pharmacol 2018;11(1):95-108.

[7] Monti JM. The role of dorsal raphe nucleus serotonergic and non-serotonergic neurons, and of their receptors, in regulating waking and rapid eye movement (REM) sleep. Sleep Med Rev 2010;14(5):319-27.

[8] Artigas F, Romero L, de Montigny C, et al. Acceleration of the effect of selected antidepressant drugs in major depression by 5-HT1A antagonists. Trends Neurosci 1996;19(9):378-83.

[9] Holmes A. Genetic variation in cortico-amygdala serotonin function and risk for stress-related disease. Neurosci Biobehav Rev 2008;32(7):1293-314. 
[10] Takeuchi Y, Kimura H, Sano Y. Immunohistochemical demonstration of the distribution of serotonin neurons in the brainstem of the rat and cat. Cell Tissue Res 1982;224(2):247-67.

[11] Petit JM, Luppi PH, Peyron C, et al. VIP-like immunoreactive projections from the dorsal raphe and caudal linear raphe nuclei to the bed nucleus of the stria terminalis demonstrated by a double immunohistochemical method in the rat. Neurosci Lett 1995;193(2):77-80.

[12] Shipley MT, McLean JH, Behbehani MM. Heterogeneous distribution of neurotensin-like immunoreactive neurons and fibers in the midbrain periaqueductal gray of the rat. J Neurosci 1987;7(7):2025-34.

[13] Smith GS, Savery D, Marden C, et al. Distribution of messenger RNAs encoding enkephalin, substance $P$, somatostatin, galanin, vasoactive intestinal polypeptide, neuropeptide $Y$, and calcitonin gene-related peptide in the midbrain periaqueductal grey in the rat. J Comp Neurol 1994;350(1):23-40.

[14] Liu Z, Zhou J, Li Y, et al. Dorsal raphe neurons signal reward through 5-HT and glutamate. Neuron 2014;81(6):1360-74.

[15] Johnson MD, Ma PM. Localization of NADPH diaphorase activity in monoaminergic neurons of the rat brain. J Comp Neurol 1993;332(4):391-406.

[16] Stamp JA, Semba K. Extent of colocalization of serotonin and GABA in the neurons of the rat raphe nuclei. Brain Res 1995;677(1):39-49.

[17] Descarries L, Watkins KC, Garcia S, et al. The serotonin neurons in nucleus raphe dorsalis of adult rat: a light and electron microscope radioautographic study. J Comp Neurol $1982 ; 207(3): 239-54$.

[18] Wickersham IR, Lyon DC, Barnard RJ, et al. Monosynaptic restriction of transsynaptic tracing from single, genetically targeted neurons. Neuron 2007;53(5):639-47.

[19] Weissbourd B, Ren J, DeLoach KE, et al. Presynaptic partners of dorsal raphe serotonergic and GABAergic neurons. Neuron 2014;83(3):645-62.

[20] Miyamichi K, Shlomai-Fuchs $Y$, Shu M, et al. Dissecting local circuits: parvalbumin interneurons underlie broad feedback control of olfactory bulb output. Neuron 2013;80(5):1232-45. 
[21] Peyron C, Petit JM, Rampon C, et al. Forebrain afferents to the rat dorsal raphe nucleus demonstrated by retrograde and anterograde tracing methods. Neuroscience 1998;82(2):44368.

[22] Paxinos G, Watson, C. The rat brain in stereotaxic coordinates. Compact 4th edition ed. Sydney, Orlando: Academic Press; 1998.

[23] Gervasoni D, Peyron C, Rampon C, et al. Role and origin of the GABAergic innervation of dorsal raphe serotonergic neurons. J Neurosci 2000;20(11):4217-25.

[24] Luppi PH, Aston-Jones $\mathrm{G}$, Akaoka $\mathrm{H}$, et al. Afferent projections to the rat locus coeruleus demonstrated by retrograde and anterograde tracing with cholera-toxin B subunit and Phaseolus vulgaris leucoagglutinin. Neuroscience 1995;65(1):119-60.

[25] Luppi PH, Fort P, Jouvet M. Iontophoretic application of unconjugated cholera toxin B subunit (CTb) combined with immunohistochemistry of neurochemical substances: a method for transmitter identification of retrogradely labeled neurons. Brain Res 1990;534(1-2):209-24.

[26] Peyron C, Tighe DK, van den Pol AN, et al. Neurons containing hypocretin (orexin) project to multiple neuronal systems. J Neurosci 1998;18(23):9996-10015.

[27] Henny P, Brischoux F, Mainville L, et al. Immunohistochemical evidence for synaptic release of glutamate from orexin terminals in the locus coeruleus. Neuroscience 2010;169(3):1150-7.

[28] Lee MG, Hassani OK, Jones BE. Discharge of identified orexin/hypocretin neurons across the sleep-waking cycle. J Neurosci 2005;25(28):6716-20.

[29] Kaur S, Pedersen NP, Yokota S, et al. Glutamatergic signaling from the parabrachial nucleus plays a critical role in hypercapnic arousal. J Neurosci 2013;33(18):7627-40.

[30] Kaur S, Wang JL, Ferrari L, et al. A Genetically Defined Circuit for Arousal from Sleep during Hypercapnia. Neuron 2017;96(5):1153-67 e5.

[31] Sapin E, Lapray D, Berod A, et al. Localization of the brainstem GABAergic neurons controlling paradoxical (REM) sleep. PLoS One 2009;4(1):e4272.

[32] Goutagny R, Luppi PH, Salvert D, et al. Role of the dorsal paragigantocellular reticular nucleus in paradoxical (rapid eye movement) sleep generation: a combined electrophysiological and anatomical study in the rat. Neuroscience 2008;152(3):849-57. 
[33] Rampon C, Peyron C, Gervasoni D, et al. Origin of the glycinergic inputs of the locus coeruleus and dorsal raphe nuclei: A study combining retrograde tracing with glycine immunohistochemistry. Eur J Neurosci 1999;11:1058-66.

\section{Legends}

TABLE 1. Quantitative distribution of retrograde-labeled neurons in the mesencephalon, the pons and the medulla following CTb injections targeting respectively the ventral or dorsal parts of the central DRN or the rostral sub-region or the lateral wings of the DRN. Quantification of CTb-labeled cells: \pm : $1-2$ cells $;+: 3-5$ cells ; $++: 6-10$ cells ; +++ : $11-20$ cells ; ++++ : $21-50$ cells ; +++++>50 cells.

FIG. 1. A, B. Photographs of frontal sections illustrating the distribution (A) of 5-HT neurons (in black) in the ventro-central, dorso-central and the lateral wings sub-regions of the DRN on a neutral red counterstained section, and (B) of the GAD-immunoreative neurons (in brown). C-F. Photographs illustrating $\mathrm{CTb}$ injection sites (in black) targeting the ventro-central (C), dorso-central (D), lateral wing (E) and rostral (F) sub-regions of the DRN where 5-HT neurons are orange-brown labeled. Abbreviations: 4: trochlear nucleus; Aq: aqueduct of Sylvius; mlf: medial longitudinal fasciculus. Scale bars $=150 \mu \mathrm{m}$.

FIG. 2. Drawings illustrating the distribution of retrograde-labeled cells in the mesencephalon after CTb injections in the ventro-central DRN (A-B), the dorso-central DRN $\left(A^{\prime}-B^{\prime}\right)$ or the lateral wings of the DRN ( $\left.A^{\prime \prime}-B^{\prime \prime}\right)$. Each black dot represents a CTb retrograde-labeled neuron. 3V: third ventricle; APT: anterior pretectal nucleus; Arc: arcuate nucleus; CG: central gray; cp: cerebral peduncle; Dk: nucleus of Darkschewitsch; IMLF: interstitial nucleus of the medial longitudinal fasciculus; EW: EdingerWestphal nucleus; fr: fasciculus retroflexus; LM: lateral mammillary nucleus; MGV: medial geniculate nucleus; ml: medial lemniscus; MM: medial mammillary nucleus; mp: mammillary peduncle; MT: tuberomammillary nucleus; pc: posterior commissure; RLi: rostral linear nucleus of the raphe; SNc: substantia nigra, compact; SNI: substantia nigra, lateral; SNr: substantia nigra, reticular; SC: superior colliculus; suM: supramammillary nucleus; sumx: supramammillary decussation; VTA: ventral tegmental area; Zl: zona incerta.

FIG. 3. Drawings illustrating the distribution of retrograde-labeled cells in the mesencephalon after CTb injections in the ventro-central DRN (A-B), the dorso-central DRN $\left(A^{\prime}-B^{\prime}\right)$ or the lateral wings of 
the DRN ( $\left.A^{\prime \prime}-B^{\prime \prime}\right)$. Each black dot represents a CTb retrograde-labeled neuron. 3: oculomotor nucleus; 3PC: oculomotor nucleus, parvicellular; Aq: aqueduct of Sylvius; CG: central gray; CLi: caudate linear nucleus of the raphe; $\mathrm{cp}$ : cerebral peduncle; dtg: dorsal tegmental bundle; DpMe: deep mesencephalic nucleus; IMLF: interstitial nucleus of the medial longitudinal fasciculus; IP: interpeduncular nucleus; MGV: medial geniculate nucleus medial; ml: medial lemniscus; mlf: medial longitudinal fasciculus; R: red nucleus; RLi: rostral linear nucleus of the raphe; RRF: retrorubral field; SNc: substantia nigra, compact; SNI: substantia nigra, lateral; SNr: substantia nigra, reticular; SC: superior colliculus; Su3: supraoculomotor nucleus.

FIG. 4. Photograph of frontal section following CTb immunoshistochemistry illustrating (A) a compact group of small-sized neurons in the ventral mesencephalic central gray (A) after CTb injection in the ventro-central sub-region of the DRN. B is an enlargement of the inner box of A. C. Photograph of the compact group of CTb-labeled neurons in the undefined nucleus located lateral to the lateral tegmental nucleus following the CTb injection in the ventro-central DRN. Scale bars $=200 \mu \mathrm{m}$. 3: oculomotor nucleus; 4V: fourth ventricle; Aq: aqueduct of sylvius; LdT: lateral tegmental nucleus; Su3: supraocculomotor nucleus.

FIG. 5. Drawings illustrating the distribution of retrograde-labeled cells in the pons after CTb injections in the ventro-central DRN (A-B), the dorso-central DRN $\left(A^{\prime}-B^{\prime}\right)$ or the lateral wings of the DRN ( $\left.A^{\prime \prime}-B^{\prime \prime}\right)$. Each black dot represents a retrograde-labeled neuron. The blacked area illustrate the CTb injection-sites. 4V: fourth ventricle; Aq: aqueduct of Sylvius; ATg: anterior tegmental nucleus; CG: central gray; CnF: cuneiform nucleus; IC: inferior colliculus; InCo: intercollicular nucleus; IP: interpeduncular nucleus; KF: Kölliker-Fuse; LdT: lateral tegmental nucleus; Ifp: Iongitudinal fasciculus of the pons; LL: lateral lemniscus ; LPB: lateral parabrachial nucleus; ml: medial lemniscus; mlf: medial longitudinal fasciculus; MnR: median raphe nucleus; PBG: parabigeminal nucleus; PMR: paramedian raphe nucleus; $\mathrm{Pn}$ : pontine nucleus; $\mathrm{PnO}$ : pontine reticular nucleus, oral ; PPT: pedunculopontin tegmental nucleus; RtTg: reticulotegmental nucleus of the pons; SC: superior colliculus; xscp: decussation of the superior cerebellar peduncle.

FIG. 6. Drawings illustrating the distribution of retrograde-labeled cells in the caudal pons after CTb injections in the ventro-central DRN $(A-B)$, the dorso-central DRN $\left(A^{\prime}-B^{\prime}\right)$ or the lateral wings of the DRN ( $\left.A^{\prime \prime}-B^{\prime \prime}\right)$. Each black dot represents a CTb retrograde-labeled neuron. 4V: fourth ventricle; $7 \mathrm{n}$, facial nerve; Bar: Barrington nucleus; DTg: dorsal tegmental nucleus; DMTg: dorsomedial tegmental 
area; LC: locus coeruleus; LdT: lateral tegmental nucleus; Ifp: longitudinal fasciculus of the pons; LL: lateral lemniscus; LPB: lateral parabrachial nucleus; LSO: lateral superior olive; mcp: middle cerebellar peduncle; MeV: mesencephalic trigeminal nucleus; ml: medial lemniscus; mlf: medial longitudinal fasciculus; MnR: median raphe nucleus; Mo5: motor trigeminal nucleus; MPB: medial parabrachial nucleus; Pn: pontine nucleus; PnC: pontine reticular nucleus, caudal; PnO: pontine reticular nucleus, oral; PnV: pontine reticular nucleus, ventral; Pr5: principal sensory trigeminal nucleus; py : pyramidal tract; RPO: rostral periolivary region; RMg: Magnus raphe nucleus; rs: rubrospinal tract; RtTg: reticulotegmental nucleus of the pons; s5: sensory root of the trigeminal nerve; scp: superior cerebellar peduncle; SubCD: subcoeruleus, dorsal; SubCV: subcoeruleus, ventral; ts: tectospinal tract; Tz: nucleus of the trapezoid body; VCA: ventral cochlear nucleus, anterior.

FIG. 7. Drawings illustrating the distribution of retrograde-labeled cells in the medulla after CTb injections in the ventro-central DRN (A-B), the dorso-central DRN $\left(A^{\prime}-B^{\prime}\right)$ or the lateral wings of the DRN ( $\left.A^{\prime \prime}-B^{\prime \prime}\right)$. Each black dot represents a CTb retrograde-labeled neuron. 4V: fourth ventricle; 6: abducens motor nucleus; 7: facial motor nucleus; 7n: facial nerve; 8n: vestibulocochlear nerve; Acs7: ascending fibers of the facial nerve; Amb: ambiguus nucleus; DPGi: dorsal paragigantocellular nucleus; g7: genu of the facial nerve; Gi: gigantocellular reticular nucleus; GiA: gigantocellular reticular nucleus, alpha; icp: inferior cerebellar peduncle; IRt: intermediate reticular nucleus; LC: locus coeruleus; LPGi: lateral paragigantocellular nucleus; LSO: lateral superior olive; LVe: lateral vestibular nucleus; mlf: medial longitudinal fasciculus; MVe: medial vestibular nucleus; PCRt: parvocellular reticular nucleus; PCRtA: parvocellular reticular nucleus, alpha; pd: predorsal bundle; $\mathrm{Pn}$ : pontine nucleus; Mo5: motor trigeminal nucleus; PnC: pontine reticular nucleus, caudal; PnV: pontine reticular nucleus, ventral; Pr5: principal sensory trigeminal nucleus; PrH: praepositus hypoglossi; py : pyramidal tract; RMg: Magnus raphe nucleus; RPa: Pallidus raphe nucleus; rs: rubrospinal tract; SO: superior olive; Sol: nucleus of the solitary tract; Sp5: spinal trigeminal nucleus; sp5: spinal trigeminal tract; SpVe: spinal vestibular nucleus; Tz: nucleus of the trapezoid body; VCA: ventral cochlear nucleus, anterior; $\mathrm{X}$ : nucleus $\mathrm{X}$. 


\section{Table 1}

Quantitative distribution of retrograde-labeled neurons in the mesencephalon, the pons and the medulla following CTb injections targeting respectively the ventral or dorsal parts of the central DRN or the rostral sub-region or the lateral wings of the DNR

$\begin{array}{lll}\text { Ventral Dorsal Rostral } & \text { Lateral wings } \\ & \text { Ipsi } \quad \text { Contro }\end{array}$

Mesencephalon

Supramammillary nucleus

Substantia nigra, compact

Substantia nigra, lateral

Substantia nigra, reticular

Ventral tegmental area

Central gray (CG)

Sub-nucleus of the ventral CG

Linear raphe nucleus

Mesencephalic reticular formation

Dorsal tegmental bundle

Central tegmental fasciculus

Superior colliculus

Supraoculomotor nucleus

$\begin{array}{ccccc}+ & ++ & ++ & + & \pm \\ ++ & +++ & +++ & ++ & + \\ \pm & \pm & \pm & + & + \\ ++ & ++++ & +++ & +++ & ++ \\ + & +++ & ++ & + & + \\ +++ & ++++ & ++++ & ++++ & ++++ \\ +++ & ++++ & +++ & +++ & ++ \\ + & + & \pm & + & + \\ +++ & ++++ & +++ & +++ & +++ \\ ++ & ++ & + & ++ & +++ \\ ++ & +++ & ++ & & + \\ + & +++ & + & +++ & ++ \\ 0 & + & \pm & ++ & ++\end{array}$

Pons

Dorsal raphe nucleus, rostral

Dorsal raphe nucleus (around site)

Dorsal raphe nucleus, caudal

Median raphe nucleus

Paramedian nucleus

Magnus raphe nucleus

CG, dorsal

CG, dorsolateral

CG, lateral

CG, ventrolateral

$\begin{array}{ccccc}++ & ++ & \text { site } & ++ & + \\ ++++ & +++ & ++++ & +++ & +++ \\ ++ & +++ & + & ++ & + \\ & + & \pm & ++ & + \\ + & ++ & +++ & ++ & ++ \\ & ++ & + & + & + \\ + & ++ & + & ++++ & +++ \\ ++ & +++ & + & +++ & +++ \\ +++ & ++++ & ++ & +++ & +++\end{array}$


CG, caudal

Pedonculopontin tegmental nucleus

Suprapedoncular tegmental nucleus

Laterodorsal tegmental nucleus

Dorsomedial tegmental nucleus

Undefined pontine nucleus

Lateral parabrachial nucleus

Medial parabrachial nucleus

Kölliker-Fuse

Locus coeruleus

Dorsal subcoeruleus

Ventral subcoeruleus

Barrington nucleus

Pontine reticular nucleus, oral

Pontine reticular nucleus, caudal

Pontine reticular nucleus, ventral

Medulla

Pallidus raphe nucleus

Gigantocellular reticular nucleus

Gigantocellular reticular nucleus, alpha

Gigantocellular reticular nucleus, ventral

Dorsal paragigantocellular nucleus

Lateral paragigantocellular nucleus

Parvocellular reticular nucleus

Parvocellular reticular nucleus, alpha

Medullaris reticular nucleus

Praepositus hypoglossi

Nucleus of the solitary tract, caudal

\begin{tabular}{|c|c|c|c|c|}
\hline+ & +++ & +++ & +++ & +++ \\
\hline+ & ++ & + & ++ & ++ \\
\hline \pm & + & \pm & + & + \\
\hline++ & +++ & ++ & +++ & +++ \\
\hline+ & \pm & \pm & ++ & + \\
\hline+++ & +++ & ++ & ++ & + \\
\hline +++++ & +++++ & +++++ & ++++ & +++ \\
\hline++ & ++ & +++ & +++ & + \\
\hline+ & ++ & +++ & +++ & + \\
\hline+ & + & \pm & \pm & \pm \\
\hline++ & +++ & ++ & ++ & ++ \\
\hline+ & + & + & ++ & + \\
\hline+ & + & + & ++ & ++ \\
\hline+++ & +++ & + & ++++ & ++++ \\
\hline+ & + & + & ++ & ++ \\
\hline \pm & + & + & + & + \\
\hline \pm & \pm & 0 & \pm & \pm \\
\hline+ & + & + & +++ & +++ \\
\hline+ & + & + & ++ & ++ \\
\hline \pm & \pm & 0 & + & \pm \\
\hline++ & ++ & ++ & ++ & ++ \\
\hline \pm & ++ & + & ++ & ++ \\
\hline+ & + & + & + & + \\
\hline+ & + & + & + & \pm \\
\hline+ & + & + & + & \pm \\
\hline \pm & \pm & \pm & \pm & + \\
\hline \pm & +++ & ++ & +++ & + \\
\hline
\end{tabular}

Quantification of CTb-labeled cells: $\pm: 1-2$ cells $;+: 3-5$ cells ; ++ : 6-10 cells ; +++ : 11-20 cells ; ++++ : 21-50 cells; $+++++>50$ cells. 